\title{
La literatura del siglo XXI: La escuela y el cine
}

\author{
Yessika María Rengifo Castillo ${ }^{1}$ \\ Héctor José Sanjuas ${ }^{2}$
}

Recibido: 24-07-2018

Aceptado: 25-09-2018

\section{RESUMEN}

El presente artículo se establece desde una reflexión sobre la literatura del siglo XXI instrumento que les permite a grandes y chicos, adentrarse a mundos posibles. Mundos que son mediados por la escuela, agente social que garantiza planteamientos críticos y propositivos. En esa dimensión, el cine se convierte en una herramienta indispensable de los procesos de enseñanza- aprendizaje, que permite identificar escenarios sociales desde el pasado, el presente, y el futuro, comprendiendo ideas, valores, y pensamientos, que construyen a los sujetos.

Palabras clave: Literatura del siglo XXI, escuela, cine.

1. Licenciada en Humanidades y Lengua castellana, Universidad Distrital Francisco José de Caldas. Especialista en infancia, cultura y desarrollo por Universidad Distrital Francisco

José de Caldas. Magister en Infancia y Cultura, de la Universidad Distrital Francisco José de Caldas. Docente.

Bogotá - Colombia.

Correo: yessikarengifocastillo@hotmail.com

ORCID: https://orcid.org/0000-0001-9940-5531

Google Académico: https://scholar.google.com/citations?user=YiKBOKAAAAAJ\&hl=es

2. Contador Público de la Universidad Nacional de Buenos Aires, ex docente Universitario, gerente en empresas de plaza, y asesor de empresas. Escritor, ensayista y poeta. Asesor y jurado Internacional de literatura del Centro Vasco Francés de Buenos Aires. Buenos Aires - Argentina.

Correo: hectorjosesanjuas@hotmail.com

ORCID: https://orcid.org/0000-0002-9362-0289

Google Académico: https://scholar.google.com/citations?user=YiKBOKAAAAAJ\&hl=es 


\title{
21 st century literature: School and cinema
}

\begin{abstract}
The present article is established from a reflection on the literature of the century XXI. Instrument that allows older and young people, to enter possible worlds. Worlds that are mediated by the school, a social agent that guarantees critical and proactive approaches. In this dimension, cinema becomes an indispensable tool of teaching-learning processes, which allows to identify social scenarios from past, present, and future. Including ideas, values, and thoughts, which built the subjects.
\end{abstract}

Keywords: Literature of the century XXI, School, Cinema.

\section{Littérature du 21 ème siècle: école et cinéma}

\section{RÉSUMÉ}

Ce document fait une réflexion sur la littérature du siècle XXlème comme instrument qui permet aux adultes et aux enfants entrer dans un autre monde possible. Les mondes qui sont intervenus par l'école, agent social qui garantit démarches critiques et proposés. Dans cette dimension le cinéma devient un outil indispensable des procès d'enseignement et apprentissage qui permet identifier les scènes sociales depuis le passé, le présent et le futur avec la compression des idées, principes et pensées qui construit aux sujets.

Des mots clés: littérature du siècle XXI, école, cinéma.

"(...) La literatura también es eso: una relación con la experiencia donde uno está al mismo tiempo viviendo y registrando" Ricardo Piglia 
La literatura es un mundo de historias. Historias que se posesionan desde personajes, lugares, y espacios, que ayudan a comprender que no todos los seres humanos son iguales (de Almeida, Santos, \& Porto, 2016). Teniendo en cuenta que todos los seres humanos están permeados de sucesos que les generan alegría, amor, melancolía, ternura, solidaridad, rencor, tristeza, etc. En palabras uno de los escritores norteamericanos más exitosos de finales del siglo XX y uno con un particular éxito entre los lectores iberoamericanos (Paul Auster 1947)

La literatura es una fuerza en el mundo y no me imagino la vida sin literatura. La vida sin arte es inimaginable, pero como todos saben, cada vez hay menos lectores. Cada vez la literatura tiene que competir con otras formas de ocio. Esto nunca me ha preocupado, porque los libros tienen algo que no tiene la música u otras formas de arte: los libros se leen individualmente. Aunque haya un lector o haya un millón, siempre hay un lector y un libro. Es una relación uno a uno, autor y lector colaborando juntos. $Y$ en cierto sentido, es el único lugar del mundo donde dos extraños pueden conocerse y reunirse en términos de igualdad. La gente habla de la muerte de la literatura, pero yo creo que no se va a producir.

Es decir, que la literatura es un universo de posibilidades que permiten abordar diferentes temáticas. Desde aspectos políticos, sociales, económicos, y culturales, del mundo (de la Calle et al., 2014).

El trazar aquí es la literatura del siglo XXI. Se hace necesario dar una definición de esta, que no suele ser sencilla. Partiendo que la literatura como el resto de las artes, presentan una ambigüedad a la hora de establecer un concepto. Teniendo en cuenta que todo en ella es arte, y que muchos autores no están de acuerdo con que se la divida en categorías. En palabras de Croce citado por (López, Tames. R. 1990. p. 15) afirma: "... No hay más literatura que la que no tiene calificativos que limiten el término" Lo que indica que la literatura es un abanico de posibilidades, que encierra un todo. Es decir, no permite ser reducida a calificativos. En ese panorama, la idea es que la literatura del siglo XXI se centra en el desarrollo humano. Sin dejar de lado, los grandes acontecimientos que abordan la vida de niños y adolescentes, desde los campos socioculturales.

Además, el escritor español Arturo Pérez Reverte (2008) señala: 
Cada vez estoy más convencido de que la mujer es el único héroe literario posible en el siglo XXI. Sobre el hombre está escrito todo. Desde Homero hasta ahora la literatura abunda en todos los aspectos del hombre como protagonista de las historias

Al respecto conviene decir que la mujer es el sujeto que determina los ámbitos culturales que se posesionan en la literatura del siglo XXI. En esa búsqueda constante de encontrar un estado de armonía, que no siempre conduce a la vida familiar, porque la realización profesional es decisiva en este siglo. En ese sentido Reverte (2008) afirma que: "Ahora hay una mujer nueva que ha irrumpido en los últimos 20, 30 o 50 años, que debe avanzar en un terreno dominado por hombres". Es decir, que la literatura del siglo XXI se caracteriza porque la mujer es el centro que deberá posesionarse en los campos sociales, culturales, económicos, y políticos, desde los procesos de enseñanza-aprendizaje (Ferreyra, 2014).

Desde esa perspectiva, la literatura del siglo XXI es un canto a los acontecimientos sociales que instaura la vida de la mujer, como sujeto sentipensante que busca un reconocimiento desde posiciones críticas, y propositivas. Según Larrosa (1998).

La idea humanista de formación, articulada conceptualmente al modo de la comprensión romántica de la experiencia estética, desarrolla justamente este proceso abierto en el que a través de las formas más nobles, fecundas y hermosas de la tradición cultural uno es llevado a sí mismo. La novela de formación, que es su articulación narrativa, cuenta la constitución misma del héroe a través de las experiencias de un viaje que, al volverse sobre sí mismo, conforma su sensibilidad y su carácter, su manera de ser y de interpretar el mundo (p. 272).

Lo cierto es que la literatura se establece como un mecanismo estético que permite acceder a espacios culturales de una nación, ayudando a definir la personalidad de los individuos (Tahull, 2016). En el caso de la literatura del siglo XXI, los pensamientos de la mujer en diferentes aspectos socioculturales.

Referida a este contexto, la relación entre la escuela y el cine, se instaura desde la transmisión de conocimientos y conductas. En donde la literatura del siglo $\mathrm{XXI}$, se instaura como un instrumento que facilita 
los procesos de enseñanza-aprendizaje (Aparicio, 2018). Procesos en los que grandes, y chicos, identifican espacios, personajes, y sucesos, que han vivido. Encontrando diferentes alternativas para superarlas, y comprendiendo que no son los únicos que las atraviesan. En ese sentido la escuela y el cine, son dos mediadores fundamentales a la hora de asumir posturas críticas y propositivas, frente a los hechos que sienten, ven, escriben, leen, y oyen, los educandos (Pérez, 2013).

A este propósito la educación se convierte en un mecanismo que garantiza los procesos de aprendizaje, que posibilita el perfeccionamiento, la superación, o desarrollo integral, del hombre en las dimensiones sociales (Langer, 2016). De acuerdo a Sarramona (2000), "la educación es un bien, vinculada a la idea de perfeccionamiento". (P. 14). Lo que indica que el proceso educativo se establece como un proceso de plenitud en los sectores socioculturales, que atraviesa el hombre. Bien, pareciera por todo lo anterior que los planteamientos de la educación son un proceso de creación, de libertad, de convivencia, y desarrollo integral (Pérez, 2014). Lo anterior indica que la educación es un mecanismo que permea todas las dimensiones cognoscitivas, acudiendo a estrategias como el cine para comprender los diferentes acontecimientos que rodean a la sociedad, y al hombre.

El cine, utilizado como instrumento de conocimientos que permite adentrarse a los campos sociales, políticos, culturales, y económicos, con el propósito de establecer procesos de interculturalidad entre los individuos. En esa misma línea, De la Torre, Pujol, y Rajadell (2005), afirman que:

El hecho de que algunas historias que llegan a través del cine tengan tanto poder e influencia sobre el público receptor, hace pensar que no se trata solo de un mero entretenimiento, sino que es necesario tenerlo en cuenta como objeto de estudio académico por parte de investigadores y docentes. Es un medio capaz de configurar mentalidades e influir creando paradigmas de actuación, sobre todo en el público infantil, que es el que nos ocupa. Y su importancia radica en que los mensajes contenidos pueden modificar el comportamiento de estos receptores de forma positiva o negativa, ya que ejercen un alto poder de persuasión debido a la escasez de edad del receptor y su falta de madurez personal. (p.14) 
Es decir, que el cine es una ruleta de posibilidades que ayuda comprender las posturas de las personas en los distintos escenarios. Tanto así que los maestros acuden a este medio para ofrecer a los educandos alternativas a la hora de abordar una misma temática. De estas circunstancias nace el hecho de que Boris Cyrulnik (2016), defina que:

Mis héroes estaban hechos de mi misma sangre, atravesábamos las mismas pruebas: el abandono, la malevolencia de los hombres y la injusticia de las sociedades. Su epopeya me contaba que era posible elevarse por encima de los días insípidos y una vida desgraciada. (P. 11)

Lo anterior refleja que el cine ofrece múltiples historias, que se caracterizan por sucesos que les ocurren a los sujetos en su diario vivir.

Según Cyrulnik (2016):

El actor del Tarzán de aquellos días se llamaba Edgar Rice Burruoghs. Nunca había ido África porque sólo le gustaba estar en los Ángeles. Esto no tenía ninguna importancia, para mí lo que contaba era la imagen de un huérfano en la jungla. Tarzán me contaba que tras la muerte de sus padres en un accidente de avión unos animales amables, sustitutos maternos, lo habían salvado para luego convertirlo en rey de la selva. En su gratitud filial, Tarzán se había vuelto su jefe para protegerlos mejor. Su infancia rota lo había expulsado de su condición humana, pero los animales lo habían humanizado. Cuando creció, la divina Jane lo civilizó enseñándole hablar en vez de gritar: "Tu Tarzán, yo Jane", le decía mientras le señalaba con su lindo dedo. Tarzán me contaba mi propia historia en términos poéticos. Mi héroe había metamorfoseado la desgracia de mi infancia en aventura mágica. Tarzán me mostraba el camino. (P. 14)

Desde esa dimensión, los héroes del cine son referentes a la hora de asumir los diferentes hechos, que les ocurren a grandes y chicos. Es decir, que gracias a una película, las personas se identifican con los protagonistas e encuentran diversas herramientas para encontrar el camino, que en ocasiones es adverso, y con múltiples de posibilidades de continuar (Konieczny, 2015). 
Cabe concluir que la escuela debe replantearse los contenidos, y las metodologías, a la hora de abordar los procesos socioculturales que enfrenta un país, y el mundo (Barrantes, Beltrán y Pérez, 2016). Lo que les permitirá a los estudiantes acudir a los medios de comunicación desde posturas críticas, y propositivas. Desde un lenguaje audiovisual que se caracteriza por códigos verbales, y no verbales, para la construcción de significados. Es decir, el fomento del desarrollo de las capacidades creativas, cognoscitivas, artísticas, y expresivas. En esa medida la literatura del siglo XXI, y el cine, se convierten en estrategias para comprender los diferentes acontecimientos que permean a los hombres como sueños y miedos, dándoles un sentido particular. Sentidos que se reflejan en los sectores políticos, sociales, culturales, y económicos, que definen el movimiento de una nación. Nada, pues, más expresivo que la afirmación del director de cine, productor, editor, guionista y actor francés, Jean Luc Godard (2012) que dice: "El arte nos atrae solamente cuando revela en nosotros secretos." Es decir, que el arte permite comprender los sucesos que acontecen a los hombres. El llamado seguirá siendo el mismo, creación de espacios dentro y fuera del aula, que fomenten y fortalezcan posturas críticas y propositivas, lo que desencadenan una mirada holística de los acontecimientos que ocurren en el mundo.

\section{Referencias bibliográficas}

Aparicio, O.Y. (2018). Las TIC como herramientas cognitivas. Revista Interamericana de Investigación, Educación y Pedagogía, RIIEP, 11(1). https://orcid.org/0000-0003-35356288

Barrantes, H. A., Beltrán, J. E. P., \& Pérez, F. A. R. (2016). Perfil del estudiante de pregrado de la Facultad de Estudios a Distancia de la Universidad Militar Nueva Granada. Revista Interamericana de Investigación, Educación y Pedagogía, RIIEP, 9(2). DOI: https://doi.org/10.22490/25391887.1948

Cyrulnik, B. (2016). (Super) héroes. ¿Por qué los necesitamos? Editorial Gedisa, S.A. Barcelona, España.

de Almeida, R. R., Santos, M. F., \& Porto, J. C. (2016). Lectura de textos ficcionales y el enfoque escolar de literatura: contribuciones para una Pedagogía de la Elección. Revista Interamericana de Educación, Pedagogía y Estudios Culturales, 9(1), 35-51. DOI: https://doi.org/10.22490/25391887.1925 
de la Calle, C. V., Malaver, M. O., Gallego, J. D. M., Rodríguez, M., Flórez, J. C., Henao, C. E. \& Saldaña, R. (2014). Aportes de los doctorados de educación en ciencia, tecnología y sociedad, desde la sistematización de sus investigaciones doctorales científicas y formativas, 2000-2010. Revista Interamericana de Investigación, Educación y Pedagogía, RIIEP, 7(1). DOI: https://doi.org/10.15332/s1657-107X.2014.0001.04

De la Torre, S. Pujol, M.A., y Rajadell, N. (2005). El cine un entorno educativo: diez años de experiencias a través del cine. Narcea. Madrid.

Ferreyra, H. A. (2014). Mesas Socioeducativas para la Inclusión y la Igualdad. Un programa "De todos con todos". Una experiencia en construcción. Revista Interamericana de Investigación, Educación y Pedagogía, RIIEP, 7(2). DOI: https://doi. org/10.15332/s1657-107X.2014.0002.01

Konieczny, P. (2015). Lorenzo García Aretio: bases, mediaciones y futuro de la educación a distancia en la sociedad digital. Revista Interamericana de Investigación, Educación y Pedagogía, RIIEP, 8(1). DOI: https://doi.org/10.15332/s1657107X.2015.0001.08

Langer, E. (2016). La construcción de confianza para el estudio de prácticas de resistencia en la escolarización de jóvenes en contextos de pobreza urbana. Revista Interamericana de Investigación, Educación y Pedagogía, RIIEP, 9(2). DOI: https://doi. org/10.22490/25391887.1945

Larrosa, J. (1998). La experiencia de la lectura. Estudios sobre Literatura y Formación. Editorial Laertes. Barcelona.

López Tamez, R. (1990). Introducción a la literatura infantil. 2 edición, Murcia: Universidad, Secretariado de Publicaciones.

Pérez, T. H. P. (2013). Aproximaciones al estado de la cuestión de la investigación en educación y derechos humanos. Revista Interamericana de Investigación, Educación y Pedagogía, RIIEP, 6(1). DOI: https://doi.org/10.15332/s1657-107X.2013.0001.05

Pérez, T. H. (2014). Colombia: de la educación en emergencia hacia una educación para el posconflicto y la paz. Revista Interamericana de Investigación, Educación y Pedagogía, RIIEP, 7(2). DOI: https://doi.org/10.15332/s1657-107X.2014.0002.06 Sarromona, J. (2000). Teoría de la Educación (Reflexión y normativa pedagógica). Ariel. Barcelona.

Tahull, J. (2016). Modernidad, educación y género. El proyecto inacabado. Revista Interamericana de Investigación, Educación y Pedagogía, RIIEP, 9(2), 159-178. DOI: https://doi.org/10.22490/25391887.1947 